\title{
A holistic integrated dynamic design and modelling approach applied to the development of ultraprecision micro milling machines
}

\begin{abstract}
Ultraprecision machines with small footprints or micro machines are highly desirable for micro manufacturing high precision micro mechanical components. However, the development of the machines is still at the nascent stage by working on an individual machine basis and hence lacks generic scientific approach and design guidelines. Using computer models to predict the dynamic performance of ultraprecision machine tools can help manufacturers substantially reduced the lead time and cost of developing new machines. Furthermore, the machine dynamic performance depends not only upon the mechanical structure and components but also the control system and electronic drives. This paper proposed a holistic integrated dynamic design and modelling approach which supports analysis and optimization of the overall machine dynamic performance at the early design stage. Based on the proposed approach the modelling and simulation process on a novel 5-axis bench-top ultraprecision micro milling machine tool - UltraMill is presented. The modelling and simulation cover the dynamics of the machine structure, moving components, control system and the machining process, and are used to predict the overall machine performance of two typical configurations. Preliminary machining trials have been carried out and provided the evidence of the approach being helpful to assure the machine performing right at the first setup.
\end{abstract}

Keywords: Integrated design; Modelling and simulation; Bench-top micro machine tool; Machine dynamics; Design optimization

\section{Introduction}

Increasing standard of machine tool performance means that machine tool developers are expected to not only concentrate on optimization of the machine tool itself in terms of the maximum speed and the precision of machine axes, but also take full account of machining processes. In other words, the machine tool developers now have to take responsibility for the overall machine's performance characteristics [1]. Therefore, when designing precision machines, it is essential to consider the interaction among the mechanical structure, control system dynamics, and machining process dynamics at an early stage [2, 3]. A holistic integrated approach is thus highly required for supporting the design of high performance precision machines, which is much needed as a methodology guide to carry out machine development in a scientific manner.

Ultraprecision machines with small footprints or micro machines are highly desirable for micro manufacturing high-precision micro mechanical components which are increasingly in demand in electro-optics, automotive, biotechnology, aerospace, and information technology industries. The development of ultraprecision micro machines is still at the nascent stage by working on an individual machine application basis and hence lacks generic scientific approach and design guidelines.

In this paper, a holistic integrated dynamic modelling and simulation approach is proposed and employed for design of a novel 5-axis bench-top micro milling machine - UltraMill. The proposed approach permits analysis and optimization of the overall machine tool dynamics and machining performance prior to prototyping. Based on the 
proposed integrated design approach, simulations were performed on two different machine configurations and their dynamic performance was evaluated. Preliminary machining trials have been carried out and provided the evidence of the approach being able to assure the machine right at the first setup.

\section{A Holistic Integrated Dynamic Design and Simulation Approach}

A typical precision machine tool may be considered to consist of five major subsystems. These are the mechanical structure, spindle and drive system, tooling and fixture system, control and sensor system, and measurement and inspection system. These sub-systems together with the machining mechanics dynamically interact and determine the machine tool's performance $[4,5]$. Traditionally, machine tool design, analysis, optimization and performance evaluation were performed on mechanical systems and control systems individually. This approach is less effective as it cannot accurately evaluate the overall machine performance.

Due to the development of machine design and drive technology, modern CNC machines can be described to an increasingly extent as a characteristic example of complex mechatronic systems. A distinguishing feature of the mechatronic system is the achievement of system functionality through intensive integration of electrical and information (software) sub-functions on a mechanical carrier [6]. Therefore, it is necessary to develop an integrated design approach in which the machine tool is treated as a complete mechatronic system to enable evaluation of the overall machine's performance at an early design stage.

Fig. 1. Schematic of the integrated dynamic design and modelling approach

Fig. 1 shows a schematic of a holistic integrated dynamic design and modelling approach for machine tool design. The design process in general starts from review of application requirements or design constraints, e.g. accuracy, cost, footprint, production rate, transport, maintenance, and so forth. To achieve the requirements, the machine tool behaviours have to be well understood at the design stage. It is believed that the machine tool behaviours and their influences on machine performance are deterministic and can be modelled and predicted [7, 8], however it is generally not possible to take all the factors contributing to the machine performance into account at the design stage due to complexity of the model and time consuming. It is important to identify a few important issues which are vital to machine performance. Obviously these issues are application dependant, but for the design of the ultraprecision micro machine tool, prioritized design issues might include motion accuracy, dynamic stiffness and thermal stability, etc. After identifying the key prioritized design issues, some design alternatives can be generated and used for performance evaluation.

The design and modelling process for performance evaluation begins from subsystem modelling alternatively termed pre-modelling, i.e. dynamic model of the machine's moving components, control system, mechanical structure, and machining processes. Different modelling strategies and simulation tools are used for these subsystems. For example, finite element analysis (FEA) is used for predicting mechanical structural response under load and model-based lumped-mass simulation is used for the control system. In order to ensure modelling accuracy and evaluate machining performance 
without real prototype, some necessary experimental tests are performed to obtain reliable data for a simulation. These may include dynamic tests on the slide and control systems to obtain dynamic parameters provided that relevant hardware has been built. Secondly, these pre-modelled parts or subsystems are integrated to represent the dynamics of the whole machine tool system. From a machining viewpoint, the main function of a machine tool is to accurately and repeatedly control the point of contact between the cutting tool and the uncut material - the "machining interface'. This interface is normally better defined as tool-workpiece loops. The position loop which refers to the relative position between the workpiece and the cutting tools directly contributes to the precision of a machine tool and directly lead to the machining errors. Deformations introduced by stiffness/compliance and thermal loop are two important aspects in tool-workpiece loops. Besides improving the performance of individual sub-systems, efforts also should be put into optimizing machine integration performance in terms of static loop stiffness, dynamic loop stiffness, etc. Therefore, the main objective of subsystem modelling is to provide necessary results and data for modelling of the entire machine tool system rather than just optimizing individual components. In this study, FEA was employed to simulate the overall machine performance by using the pre-modelled results. The machine performance predicted from simulation is then used for the design decision process, corresponding modifications and optimizations being made to fulfil the design requirement as illustrated in Fig. 1.

\section{Subsystems Modelling}

The proposed integrated dynamic design and modelling approach has been applied to the design and optimization process of the UltraMill for manufacturing micro parts. The machine discussed here is a bench-top micro milling machine using aerostatic bearings and direct drive motors on all linear and one rotational. These axes also incorporate squeeze film dampers to absorb vibrations and enhance dynamic performance. The design goal was to build a bench-top ultraprecision machine capable of submicron precision and nanometric surface finishes.

\subsection{Modelling of the Machine's Mechanical Structure}

During individual machine components design stage, the influences of the dynamics of machine mechanical structures, such as machine frame, machine bed and the housing to supporting structures cannot be neglected. Proper modelling and analysis of these mechanical structures is critical since the mechanical structure not only provides the support and accommodation for all the machine's components but also contributes to dynamics performance. To achieve high stiffness, damping and thermal stability, two major design issues are involved in mechanical structure design, i.e. material selection and configuration. ANSYS codes were utilized to represent machine mechanical structures in this study. Various feasible materials (polymer concrete, natural granite, and cast iron, etc.) and frame configurations (open frame, closed gantry type, etc.) have been analyzed and compared.

\subsection{Modelling of the Direct Feed Drive and Electrical Components}

Aerostatic bearings and linear motor direct drive technology have been used on all linear axes. Direct drive aerostatic bearing slides offer the advantage of accurate 
dimensional control and higher acceleration and velocity compared to the screw-based drive systems [9-11]. However, the cutting forces in machining are directly applied to their linear drive motors due to the absence of mechanical transmissions. In order to achieve high machining accuracy and surface finish, a high stiffness drive is therefore desirable. The stiffness of direct drives is primarily dependant on the control system, the drive motor, amplifier and encoder. Cutting forces during machining may not be constant due to machine vibration, chatters and any other disturbance. A fast varying cutting force requires robust disturbance rejection ability from the controller. Therefore, the dynamic stiffness of a servo loop becomes very important in achieving high performance micro machining. An accurate dynamics model is necessary to predict dynamic performance in the feed direction of the slide. The direct drive control system model used is shown in the block diagram of Fig.2.

Fig. 2. Block diagram of the direct drive system

The direct drive system comprises a controller (PID and feedforward servo algorithm), a drive amplifier, a linear motor, an encoder, and the aerostatic bearing slide. $U_{M}$ is the control signal from the controller that is applied to the input of the drive amplifier. Because the dynamic response of the amplifier was assumed to be much faster than that of the motor, it was modelled to have a unity gain, $K_{A}(\mathrm{~A} / \mathrm{V})$. The thrust force, $F_{M}(\mathrm{~N})$, produced by the linear motor is proportional to the input current, $I_{M}(\mathrm{~A})$, produced by the drive amplifier. The dynamic response of the electrical components in the linear motor was neglected. Apart from the thrust force applied to the slide, the slide is also subjected to the disturbance force $F_{d}(\mathrm{~N})$, which contains cutting forces, friction forces, etc. Due to the friction free slide system used in this study, cutting forces become the dominant disturbing forces. The mechanical system including additional moving mass, $M$, was modelled as a second order undamped system. The governing equation of the feed drive can be written as:

$$
K_{F} I_{M}=F_{M}=F_{d}+M \frac{d^{2} x}{d t^{2}}
$$

The PID controller used is in a practice structure which is different from the form of the classical PID as shown in Fig. 2. In this PID structure, the integral gain $K_{I}$ acts on the position error, the derivative gain $K_{D}$ operates on the derivative of the actual position rather than error signals, and the proportional gain $K_{P}$ is implemented as an overall gain, post-multiplying the other gains for ease of adjustment if external gains change.

The following transfer functions are obtained from Fig. 2:

(1) without feedforward filter:

$$
\begin{aligned}
& G_{1}(s)=\frac{X(s)}{R(s)}=\frac{K_{i} K_{P} K_{A} K_{F}}{M s^{3}+\left(K_{I}+K_{D} s^{2}\right) K_{P} K_{A} K_{F} E(s)} \\
& G_{2}(s)=\frac{X(s)}{F_{d}(s)}=\frac{s}{M s^{3}+\left(K_{I}+K_{D} s^{2}\right) K_{P} K_{A} K_{F} E(s)}
\end{aligned}
$$

(2) with feedforward filter, $\mathrm{G}_{\mathrm{ff}}(\mathrm{s})$ :

$$
\begin{aligned}
& G_{3}(s)=\frac{X(s)}{R(s)}=\frac{\left(K_{I}+G_{f f}(s) \cdot s\right) K_{P} K_{A} K_{F}}{M s^{3}+\left(K_{I}+K_{D} s^{2}\right) K_{P} K_{A} K_{F} E(s)} \\
& G_{4}(s)=\frac{X(s)}{F_{d}(s)}=\frac{s}{M s^{3}+K_{I} K_{P} K_{A} K_{F}\left(1+\frac{K_{D}}{K_{I}}\right) E(s)}
\end{aligned}
$$


Where the transfer functions $\mathrm{G}_{2}(\mathrm{~s})$ and $\mathrm{G}_{4}(\mathrm{~s})$ represent the servo dynamic stiffness of the direct drive with and without the feedforward filter respectively. The parameters used in the modelling were determined as follows: the system mass was determined by slide geometry; the damping value was found via frequency response curve fitting techniques; controller parameters were determined using simulation optimization; the remaining parameters were obtained from the manufacturers data.

A Matlab/Simulink model was derived from the block diagram and individual axis dynamics were obtained from Simulink simulation. Impulse response tests on a direct drive linear slide were performed to validate simulation results. Both static and dynamic stiffness of the slide in the driving direction have been determined. Corresponding stiffness data has been imported to the FEA model for evaluating the machine dynamics.

\subsection{Modelling of the Air Bearings}

Air bearings are used on all three linear axes and one rotary axis on the bench-top machine. The overall machine performance significantly depends on the static and dynamic stiffness of the air bearings. A practical and accurate computational model was established for simulation of air bearings. As shown in Fig. 3, the carriage and base of the slideway were modelled as 3D solid elements, while between them a set of spring elements were located to simulate air bearings. The 'normal' and 'tangential' springs simulate the stiffness of the air bearing in the normal and tangential directions respectively. A linear spring property was assumed because properly designed air bearings have very linear load-deflection characteristics under small amplitude deflections. Stiffness and damping of the air bearings were determined and substituted into the FEA model for dynamic analyses.

Fig. 3. An equivalent FE model for air bearing slideway. (a) the linear spring element; (b) an example of air bearing slide

\subsection{Modelling of the Micro-milling Force}

It is not the purpose of this paper to develop a detailed micro-cutting force prediction model. However it is intended to estimate cutting force levels at typical cutting conditions and then evaluate the machine dynamic response under various loads. Although there are a number of complex analytical milling force models available $[12,13]$, in this study a simplified peak and average force model was chosen. According to [14], the peak resultant milling force $F_{R, \text { Peak }}$ can be simply expressed as

$$
F_{R, \text { peak }}=F_{R}^{*} f^{m_{R 1}} d_{e}^{m_{R 2}} d_{A}^{m_{R 3}} V^{m_{R 4}}+F_{R 0}
$$

Where, $f$ is feed per flute, $d_{e}$ and $d_{A}$ are radial and axial depths of cut, and $V$ is the cutting speed. $F_{R}^{*}, F_{R 0}, m_{R j}(\mathrm{j}=1$ to 4$)$ are constants related to workpiece materials and are derived from corresponding experimental data.

The $\mathrm{X}$ and $\mathrm{Y}$ force components obtained from equation (6) are

$$
\begin{aligned}
& F_{X p}=F_{R, p e a k} \sin \theta_{R} \\
& F_{Y p}=F_{R, \text { peak }} \cos \theta_{R}
\end{aligned}
$$

Where $\theta_{R}$ is the peak immersion angle. Detailed model derivation can be found in [14]. 


\section{Performance Analysis of the Bench-Top Micro Milling Machine}

After obtaining the dynamic response of the pre-modelled subsystems, the integrated 3D FEA model which takes full account of the dynamics of the mechanical structure, machine moving components, control system, and the machining process was established. The goal of the 3D integrated modelling is to accurately evaluate and optimize the dynamic performance of the overall machine.

In order to optimize the dynamic performance, different arrangements of axes have been explored together with different materials combinations which correspond to different machine design configurations. Two typical configurations - open frame structure and closed frame structure are discussed below. Fig. 4 shows the geometry and coordinate definition of the two alternatives studied. Because there are 3 translational axes in the machine tool, at least two axes will have to be stacked either on the tool or on the workpiece side. In the open frame configuration, air bearing slides at $\mathrm{X}$ and $\mathrm{Y}$ axes are stacked together and the $\mathrm{Z}$ axis air bearing slide is mounted on the column vertically at one corner of the machine bed. In the closed frame (or gantry type) configuration the $\mathrm{X}$ axis and $\mathrm{Z}$ axis slides are stacked together, and the box type air bearing slide ( $\mathrm{X}$ axis) replaces the dovetail type slide in the open frame configuration. Static analysis, modal analysis and harmonic analysis were conducted on the two configurations respectively.

Fig. 4. Two typical machine configurations and their coordinate definition

Mechanical properties for the structural deformable materials used in the FEA are summarized in Table 1. Some initial stiffness inputs for $\mathrm{Y}$ axis used for the integrated analysis are listed in Table 2 as an example. These initial stiffness values are predicted from simulation or air bearing calculation and have been validated by static and dynamic tests.

Table 1. Mechanical properties of materials used in FEA

Table 2. Some initial stiffness input for $\mathrm{Y}$ axis used for the integrated analysis

\subsection{Static Analysis}

A set of known forces in three directions were applied to the positions of the cutting tool and worktable to calculate the relative static deflection between tool tip and workpiece which will eventually influence machining accuracy. The structural loop stiffness in three directions, which characterizes the machine's overall static performance, was calculated by the static analysis and is shown in Fig. 5. It should be noted that the stiffness results are comparatively low because the analysis take the stiffness of the air bearings and the linear motors into account.

It can be found from Fig. 5 that there are substantial differences between open and closed frame configurations apart from the static loop stiffness in the $\mathrm{x}$ direction (y-z plane). In the $\mathrm{x}$ direction the loop stiffness for the two configurations is very close. $\mathrm{X}$ slide (box type) in the closed frame configuration provide better rigidity and its pitch deflection is a smaller proportion of the total deflection. But compared to the open frame there is too much overhang on the $\mathrm{z}$ slide, which introduces substantial 
deflection. In the y direction (z-x plane) and $\mathrm{z}$ direction (x-y plane), the loop stiffness of the closed frame configuration is higher than that of the open frame, which can be attributed to rolling and pitch rigidity enhancement of the $\mathrm{x}$ axis box type slide even though there exists overhang on $\mathrm{z}$ slide.

Of all the components in the structural loop, the servo stiffness of each individual axis which was predicted from subsystem modelling is the weakest and contributes to the deflection most. For both configurations, frame deflection contributes very little to total deflection. From a machine structural optimization point of view, it is more important to optimize the slide arrangement rather than the rigidity of the machine frame. In addition, different frame materials - natural granite, polymer concrete and cast iron, have been used in the FEA model and no significant difference was observed. Therefore, the mechanical properties of frame materials have little effect on the static performance of the machine being built although they should affect the machine's dynamic performance and thermal stability.

Fig. 5. Structural loop stiffness calculated from static FEA

\subsection{Modal Analysis}

Modal analysis determines the fundamental vibration mode shapes and corresponding frequencies. In this study, the first ten natural frequency and their vibration mode shapes were extracted for both configurations using the block Lanczos method. Table 3 lists the first ten natural frequencies and the description of the mode for the benchtop micro milling machine. Higher order vibration shapes $\left(8^{\text {th }}\right.$ to $10^{\text {th }}$ mode) are regarded as combined shapes and are difficult to describe. Detailed pictorial descriptions of first vibration mode for two configurations are shown in Fig. 6(a) and (b).

Table 3. First 10 natural frequencies of the bench-top micro milling machine

Modal FEA results show that the lowest natural frequency was found on the y axis slide for the open frame configuration and the $\mathrm{z}$ axis slide for the closed frame configuration respectively. Both of them are attributed to a 'stacked tilting effect', i.e. the stack of slides assembled on the top of each other (stack of $x$ slide on $y$ slide in the open frame case and stack of $\mathrm{z}$ slide on $\mathrm{x}$ slide in the closed frame case), and therefore stacked slides become the weakest part in both configurations as illustrated in Figure 6(a) and 6(b). The first natural frequency in the closed frame case $(129.43 \mathrm{~Hz})$ is higher than that in the open frame case $(117.50 \mathrm{~Hz})$ due to the higher stiffness of the $\mathrm{x}$ slide box type air bearing, indicating a better dynamic performance. In the frequency range of $0-300 \mathrm{~Hz}$, seven vibration modes occur in the open frame configuration and all three slide vibration modes are excited, while only four vibration modes occur in the closed frame configuration and only the $\mathrm{z}$ axis vibration mode is excited. This indicates that the open frame configuration is more sensitive to the vibration than the closed frame. The harmonic analysis performed on both configurations confirms this conclusion. The stiffness of the air bearings and servo drives dominate the lower natural frequencies and vibration modes, while machine frame vibration has not been excited in the lower frequency range for both configurations. Increasing the stiffness and optimizing arrangement of air bearings are the most effective way to enhance the machine's dynamic performance. It should be noted that in conventional precision machine design, the first natural frequency is expected to be higher than the machine operation frequency [15], for example, the spindle rotational frequency. However, it 
cannot be the case in ultraprecision micro milling machine, because the maximum spindle speed in micro milling machine can be up to $4000 \mathrm{~Hz}(240,000 \mathrm{rpm})$. Modal analysis results provide a machine operation frequency selection guide rather than a threshold for maximum spindle speed.

Fig. 6. First natural frequency and its vibration mode

\subsection{Harmonic Response Analysis}

After indentifying the natural frequencies and their modes of vibration, harmonic response analyses were performed to quantitatively determine the steady-state response of the machine to loads that vary harmonically with time. The harmonic response analysis is able to verify whether or not the designs will successfully overcome resonance and harmful effects of forced vibrations. Equivalent resultant forces predicted by micro milling force modelling were converted into harmonic form and applied to the machine.

In this analysis, the machine structure was excited by a series of harmonic forces $F$ acting between workpiece and cutting tool:

$$
F=F_{0} \sin (\omega t) \omega=20 i(i=1,2,3, \ldots, 25)
$$

An average cutting force $F_{0}$ of 1 Newton was assumed and a frequency range from 20 to $500 \mathrm{~Hz}$ with $20 \mathrm{~Hz}$ intervals was chosen so as to give an adequate response curve. Fig. 7(a)-(c) provide the harmonic response of relative displacement between cutting tool and workpiece in three directions respectively. For the open frame configuration the maximum dynamic compliance of about $0.615 \mu \mathrm{m} / \mathrm{N}$ (x direction) occurs at $120 \mathrm{~Hz}$, which corresponds to a dynamic loop stiffness of $1.63 \mathrm{~N} / \mu \mathrm{m}$. For the closed frame configuration the maximum dynamic compliance of about $0.32 \mu \mathrm{m} / \mathrm{N}$ ( $\mathrm{x}$ direction) occurs at $140 \mathrm{~Hz}$, which corresponds to a dynamic loop stiffness of 3.13 $\mathrm{N} / \mu \mathrm{m}$. In the medium frequency range of $200-500 \mathrm{~Hz}$, a highest dynamic stiffness of about $3 \mathrm{~N} / \mu \mathrm{m}$ and $4 \mathrm{~N} / \mu \mathrm{m}$ were found for closed and open frame configurations respectively. Over the whole frequency range $(0-500 \mathrm{~Hz})$ analyzed, the closed frame configuration yielded lower dynamic compliance and fewer resonances than the open frame configuration. More evenly distributed vibration peaks from the closed frame response curve were found and they indicated a better slide arrangement.

Fig. 7. Harmonic response of the bench-top micro-milling machine

Fig. 8. The bench-top micro milling machine

From the analysis and comparison between the two machine alternatives above, the closed frame configuration was found to be much better than the open frame configuration in terms of static loop stiffness, dynamic loop stiffness, and natural frequencies. A prototype bench-top micro milling machine has been built based on the closed frame configuration whose volumetric size is $780 \times 650 \times 470 \mathrm{~mm}$ as illustrated in Fig. 8.

\section{Specifications of the UltraMill}


The UltraMill, Fig.8, offers the capability of manufacture of 3D miniature mechanical components and micro-featured surfaces in a wide range of engineering materials in a small footprint. The main specifications of the UltraMill are summarized in Table 4.

Table 4. Specifications of the micro milling machine - UltraMill

\section{Preliminary Machining Trials on the UltraMill Machine}

Fig. 9. The samples and applications machined with micro cutting tools

Fig. 10. Straightness measurement result (over 40mm) using the Carl Zeiss F25 CMM

The Ultramill machine has been utilized to machine micro and miniature components and products with features at both nanometric and micro levels on a variety of engineering materials including $\mathrm{Cu}, \mathrm{Al}$, Silicon, steal, etc. The samples and applications shown in Fig. 9 are machined with tungsten carbide, CVD and diamond micro cutting tools respectively. A surface roughness $\mathrm{Ra}$ of $10 \mathrm{~nm}$ using diamond tools has been obtained from micro slot milling, and a straightness of $0.28 \mu \mathrm{m}$ over 40mm was measured on a X-Y linear interpolation machined slot using a Carl Zeiss F25 micro CMM as shown in Fig. 10. The preliminary machining results illustrate the machine capability in producibility and productivity after the first setup. This provides the evidence of the feasibility and robustness of the proposed integrated design approach, although more trials are needed to test the machine performance comprehensively in light of ISO standards against a variety of applications. A separate paper will discuss these micro machining experiments using various cutting tools.

\section{Concluding Remarks}

A holistic integrated dynamic modelling and design approach has been successfully developed for analysis and optimization of a bench-top ultraprecision micro milling machine - UltraMill throughout its design process. The approach covers the dynamics of the machine structure, moving components, control system and the cutting process and provides the comprehensive analysis on the performance of the entire machine at design stage without the need for prototyping. A series of simulations performed on two typical machine configurations, including the static analyses, modal analyses and harmonic analyses, have predicted the machine's static and dynamic loop stiffness and proved the approach valid and industrial feasible. The simulations based on the approach are used as a powerful tool for supporting the full design process in an iterative manner, which also enable the machine design to be optimized efficiently and effectively. The results from this paper provide a benchmark and systematic methodology for designing next and future generation of ultraprecision micro machines, especially those using direct drive linear motors combined with aerostatic bearings.

The computation of thermal performance is necessarily incorporated into the static and dynamic analyses of the machine tool. Future efforts will be directed towards predicting the thermal performance of the overall machine system, by combining with cutting trials.

\section{Acknowledgements}


The authors are grateful for the support of the EU 6th Framework NMP Program under the contract number NMP2-CT-2-4-500095. Thanks are due to all partners of MASMICRO project consortium and to those within the RTD 5 subgroup in particular. The authors would also like to thank Mr. Paul Yates, Mr. Lei Zhou and Mr. Khalid Nor at Brunel University for their assistance in the work.

\section{References}

[1] Zaeh, M. and Siedl, D. A new method for simulation of machining performance by integrating finite element and multi-body simulation for machine tools. Annals of the CIRP, 2007, 56(1), 383-386.

[2] Maj, R., Modica, F. and Bianchi, G. Machine tools mechatronic analysis. Proceedings of the Institution of Mechanical Engineers, Part B: Journal of Engineering Manufacture, 2006, 220(3), 345-353.

[3] Bianchi, G., Paolucci, F., Van den Braembussche, P. and Van Brussel, H. Towards virtual engineering in machine tool design. Annals of the CIRP, 1996, 45(1), 381-384.

[4] Huo, D. and Cheng, K. A dynamics-driven approach to the design of precision machine tools for micro-manufacturing and its implementation perspectives. Proceedings of the Institution of Mechanical Engineers, Part B: Journal of Engineering Manufacture, 2008, 222(1), 1-13.

[5] Luo, X., Cheng, K., Webb, D. and Wardle, F. Design of ultraprecision machine tools with applications to manufacture of miniature and micro components. Journal of Materials Processing Technology, 2005, 167(2-3), 515-528.

[6] Reinhart, G and Weissenberger, M. Multibody simulation of machine tools as mechatronic systems for optimization of motion dynamics in the design process. Proceedings of the IEEE/ASME International Conference on Advanced Intelligent Mechatronics, AIM, 1999, 605-610.

[7] Bryan, J. B, the power of deterministic thinking in machine tool accuracy. Proceeding of the first International Machine Tool Engineers Conference. 1984.

[8] Slocum, A. H. Precision Machine Design, 1992 (Englewood Cliffs, Prentice Hall)

[9] Otten, G., De Vries, T. J. A., Van Amerongen, J., Rankers, A.M. and Gaal, E.W. Linear motor motion control using a learning feedforward controller. IEEE/ASME Transactions on Mechatronics, 1997, 2(3), 179-187.

[10] Weidner, C. and Quickel, D. High speed machining with linear motors. Manufacturing Engineering, 1999, 122(3): 80-90.

[11] Denkena, B., Tönshoff, H. K., Li, X., Imiela, J. and Lapp, C. Analysis and control/monitoring of the direct linear drive in end milling, International Journal of Production Research, 2000, 42(24), 5149-5166.

[12] Vogler, M. P., Kapoor, S. G. and DeVor, R. E. On the modeling and analysis of machining performance in micro-endmilling, part II: Cutting force prediction. Journal of Manufacturing Science and Engineering, Transactions of the ASME, 2004, 126(4), 695-705.

[13] Vogler, M. P., DeVor, R. E. and Kapoor, S.G. Microstructure-level force prediction model for micro-milling of multi-phase materials. Journal of Manufacturing Science and Engineering, Transactions of the ASME, 2003, 125(2), 202-209.

[14] Childs, T. H. C., Maekawa, K., Obikawa, T. and Yamane, Y. Metal Machining: Theory and Applications. John Wiley \& Sons Inc. 2000 
[15] Shore, P., Morantz, P., Luo, X., Tonnellier, X., Collins, R., Roberts, A., MayMiller, R. and Read, R. Big optix ultraprecision grinding/measuring system. Proceedings of SPIE - The International Society for Optical Engineering, 2005, 59650, Q1-8. 
Figures and tables

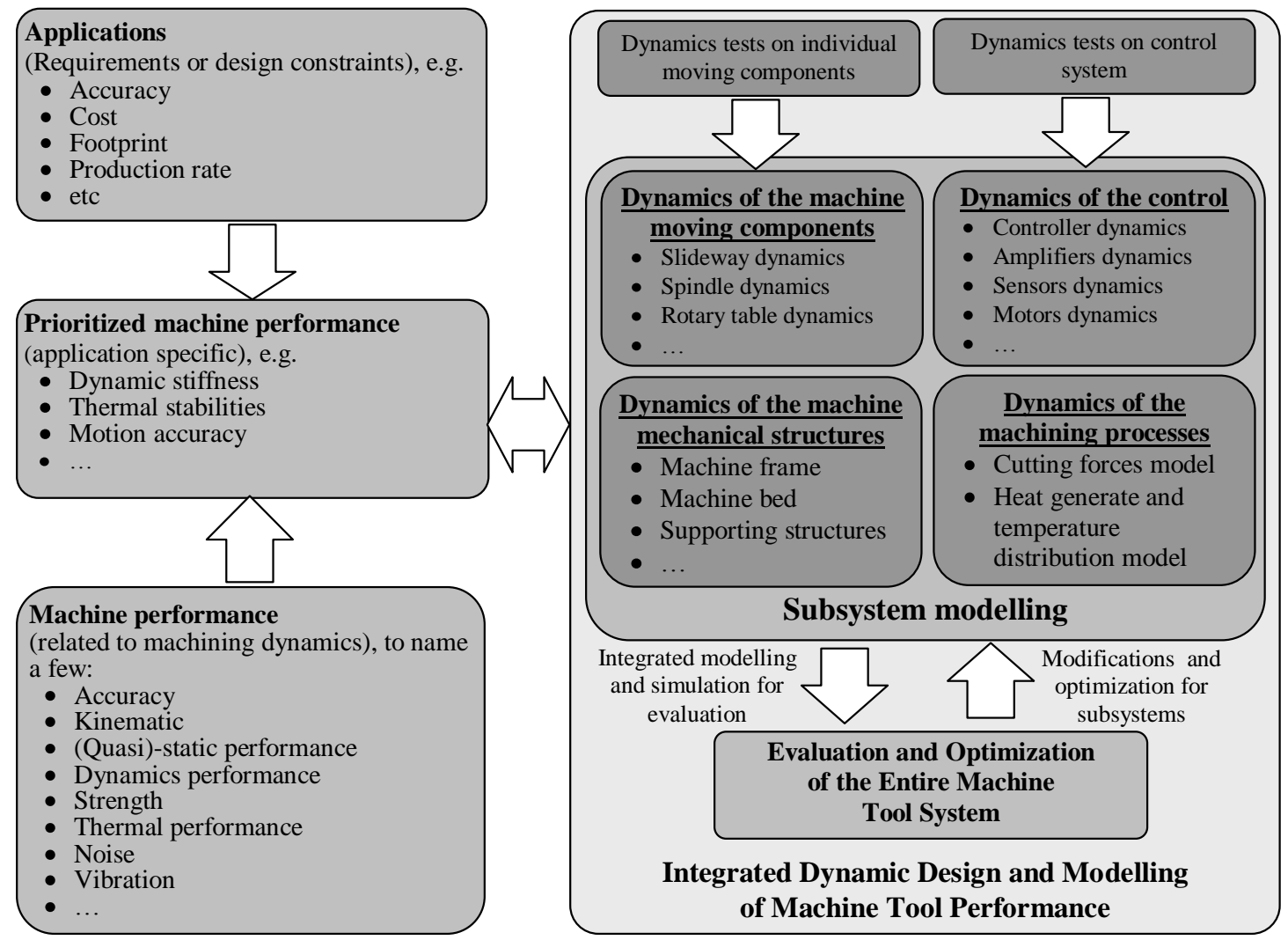

Fig. 1. Schematic of the integrated dynamic design and modelling approach 


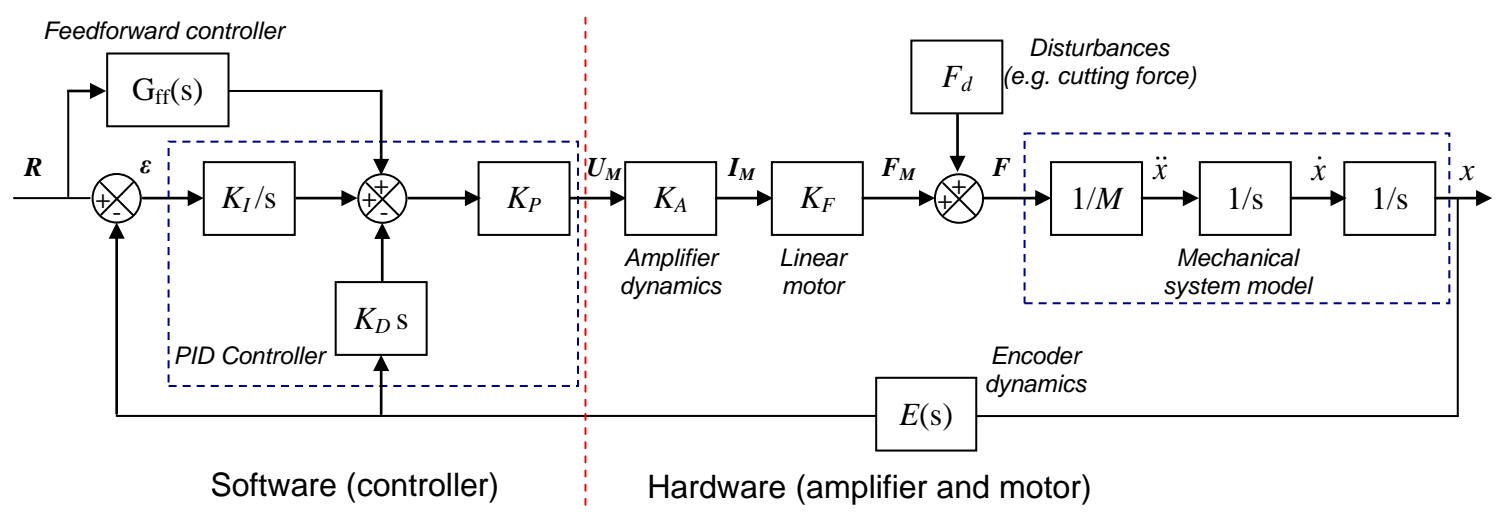

Fig. 2. Block diagram of the direct drive system 


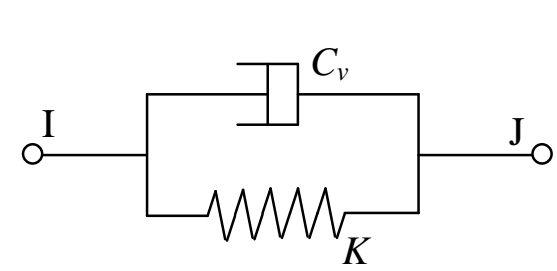

(a)

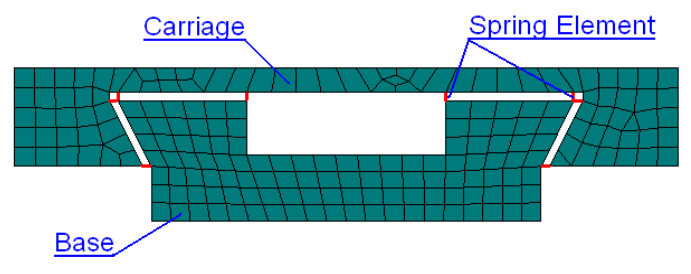

(b)

Fig. 3. An equivalent FE model for air bearing slideway. (a) the linear spring element; (b) an example of air bearing slide 


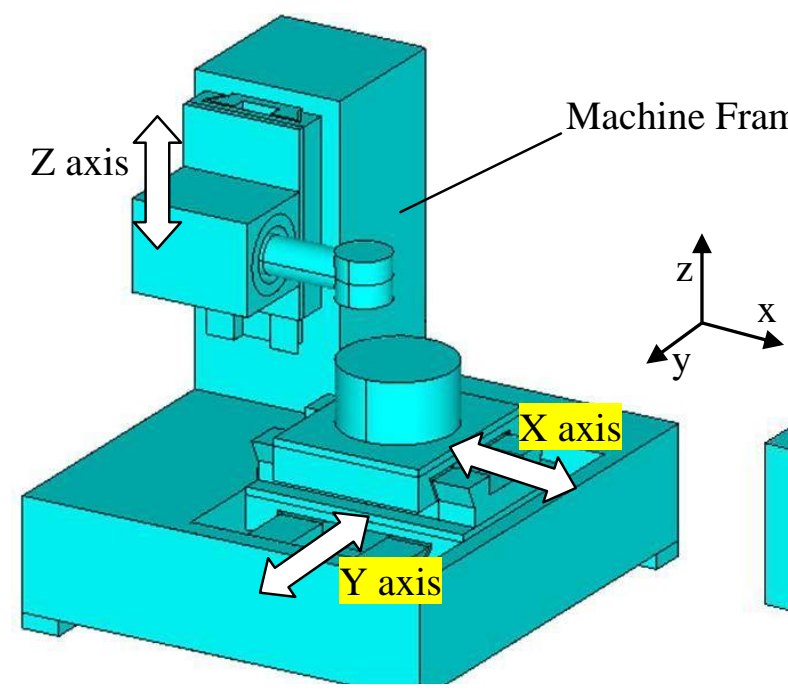

(a) Open frame

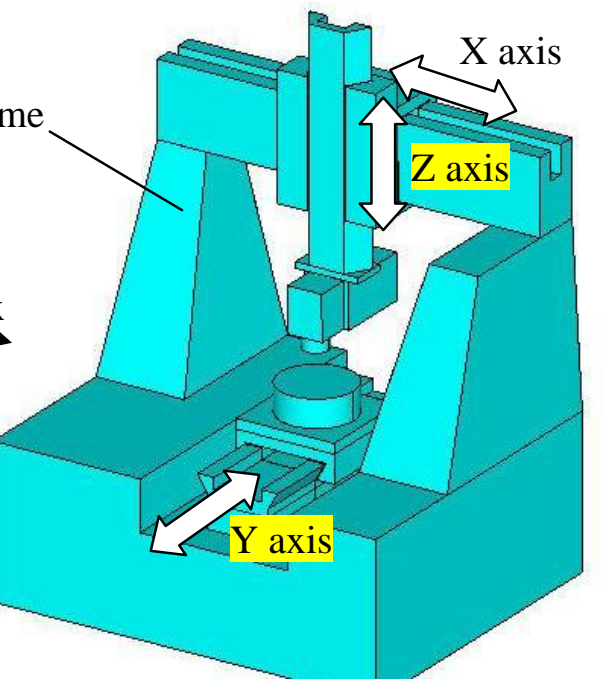

(b) Close frame

Fig. 4. Two typical machine configurations and their coordinate definition 


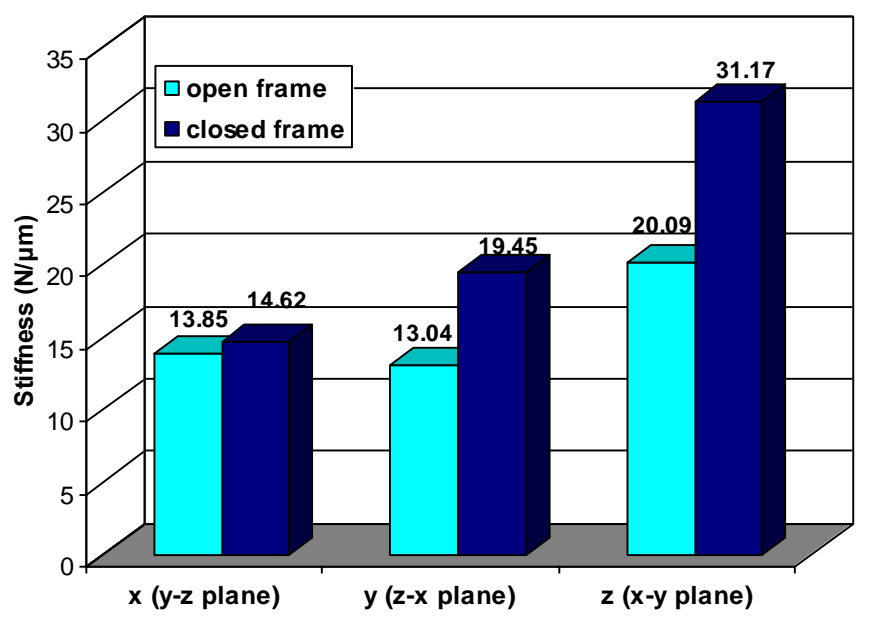

Fig. 5. Structural loop stiffness calculated from static FEA 


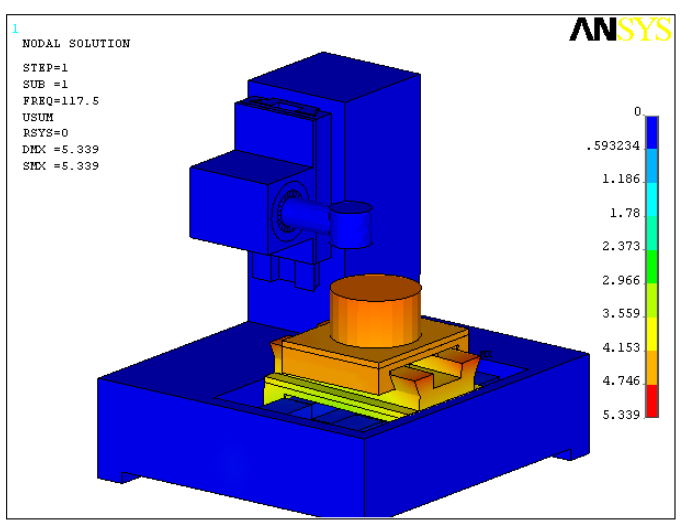

(a)open frame

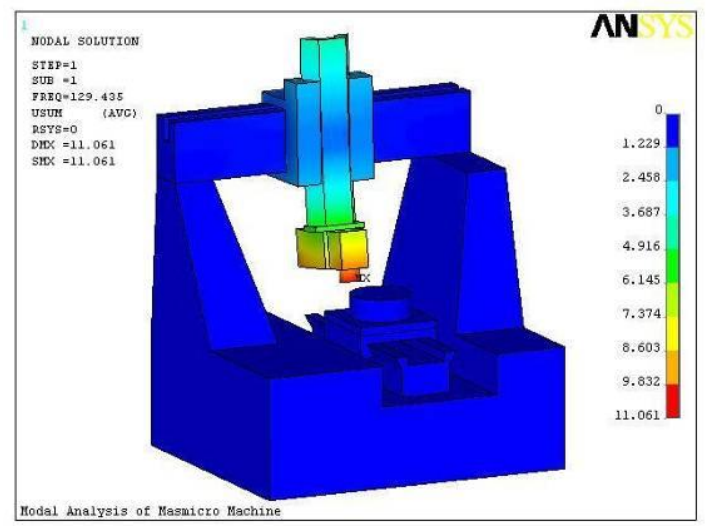

(b) closed frame

Fig. 6. First natural frequencies and their mode 


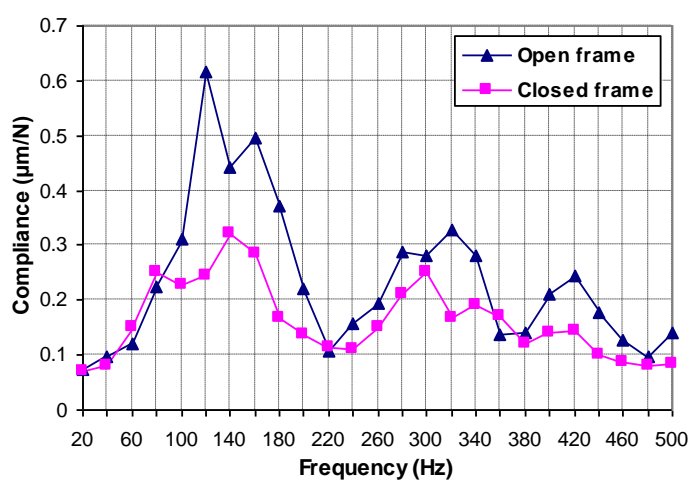

(a) $\mathrm{x}$ direction ( $\mathrm{y}-\mathrm{z}$ plane)

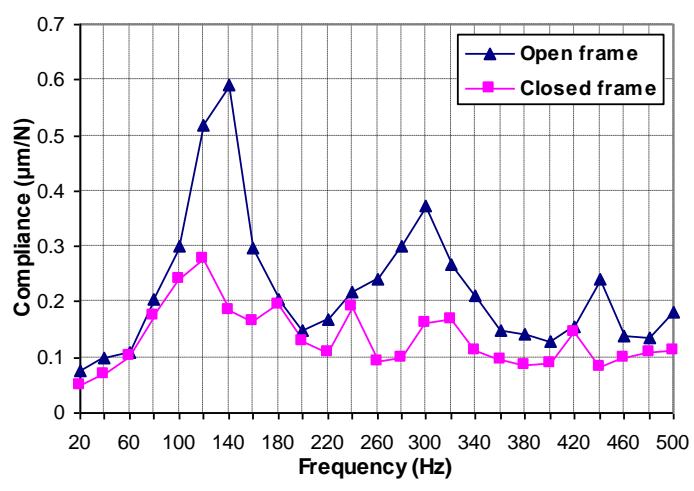

(b) y direction (z-x plane)

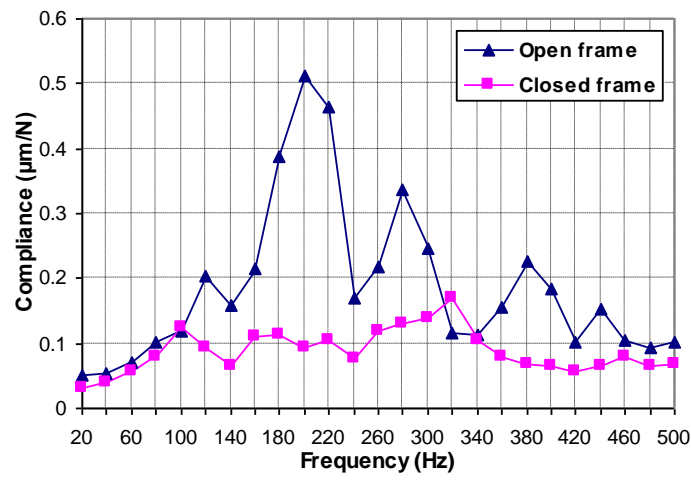

(c) $\mathrm{z}$ direction ( $\mathrm{x}-\mathrm{y}$ plane)

Fig. 7. Harmonic response of the bench-top micro-milling machine 


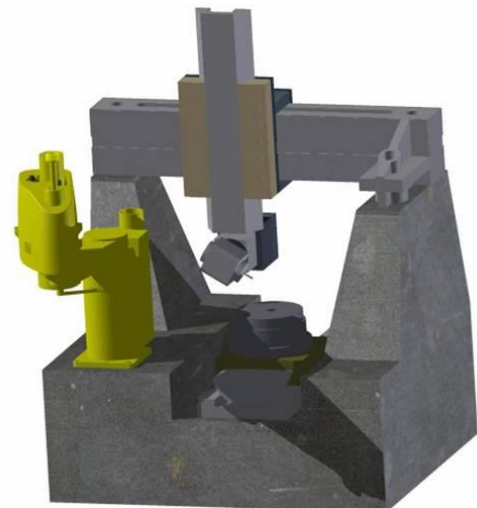

(a) 3D CAD model

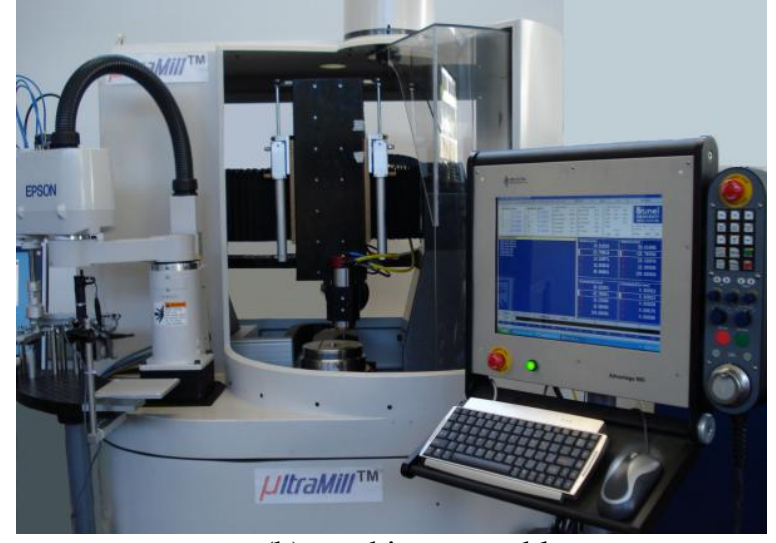

(b) machine assembly

Fig. 8. The bench-top micro milling machine 


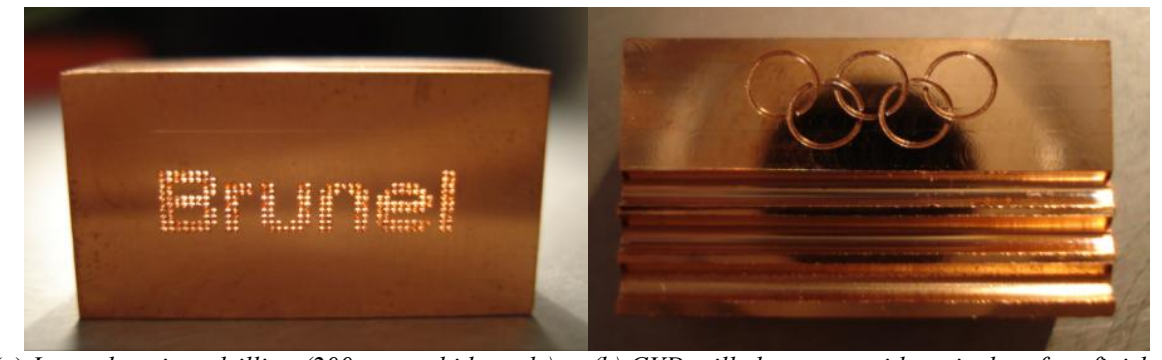

$\begin{array}{ll}\text { (a) Logos by micro drilling (200 } \mu \mathrm{m} \text { carbide tools) } & \text { (b) CVD milled grooves with optical surface finish }\end{array}$

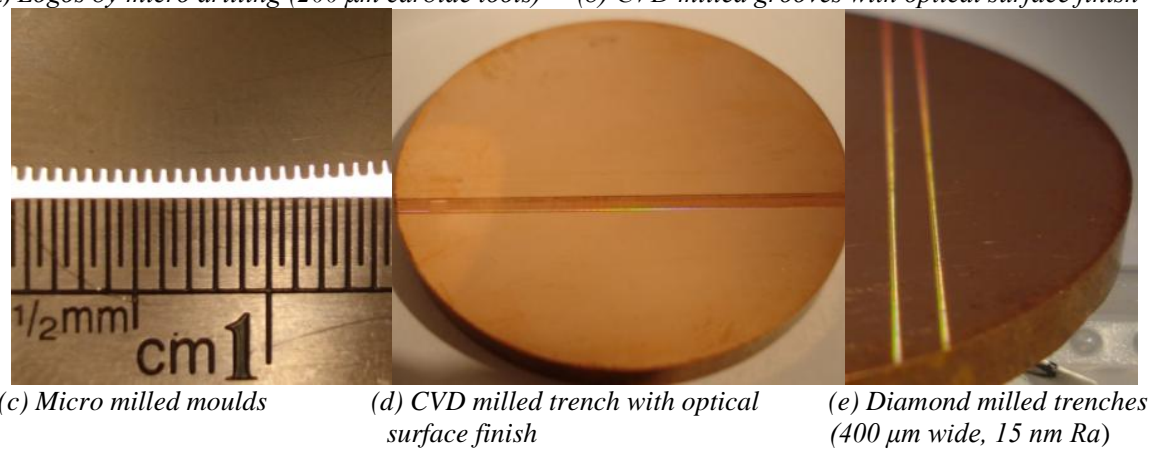

Fig. 9. The samples and applications machined with micro cutting tools 


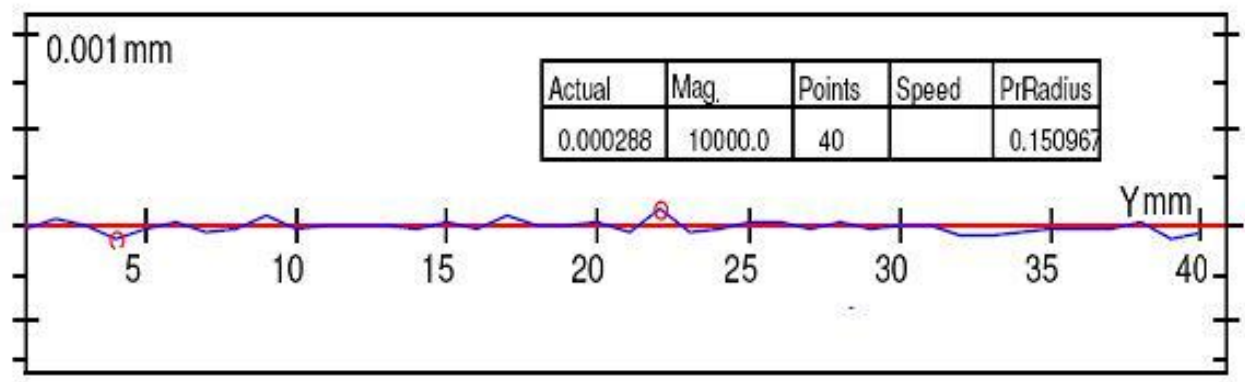

Fig. 10. Straightness measurement result (over 40mm) using the Carl Zeiss F25 CMM 
Table 1. Mechanical properties of materials used in FEA

\begin{tabular}{cccc}
\hline & Density $\left(\mathrm{Kg} / \mathrm{m}^{3}\right)$ & Elastic Modulus $(\mathrm{GPa})$ & Poisson's ratio \\
\hline Bronze SAE 660 & 8930 & 117 & 0.34 \\
\hline Steel 431 & 7800 & 200 & 0.30 \\
\hline Natural Granite & 2600 & 50 & 0.25 \\
\hline Aluminium Alloy 2014 & 2800 & 80 & 0.33 \\
\hline Polymer concrete & 2450 & 45 & 0.3 \\
\hline Cast Iron & 7850 & 170 & 0.27 \\
\hline
\end{tabular}


Table 2. Some initial stiffness input for Y axis used for the integrated analysis

\begin{tabular}{|c|c|c|c|c|c|c|}
\hline & \multirow{2}{*}{$\begin{array}{c}\text { Drive } \\
\text { stiffness } \\
K_{r}(\mathrm{~N} / \mu \mathrm{m})\end{array}$} & \multicolumn{5}{|c|}{ Air bearings } \\
\hline & & $\begin{array}{c}\text { Vertical } \\
K_{z} \\
(\mathrm{~N} / \mu \mathrm{m})\end{array}$ & $\begin{array}{c}\text { Lateral } \\
K_{x} \\
(\mathrm{~N} / \mu \mathrm{m})\end{array}$ & $\begin{array}{c}\text { Torsional } \\
K_{y y} \\
(\mathrm{Nm} / \mathrm{rad}))\end{array}$ & $\begin{array}{c}\text { Torsional } \\
K_{x x} \\
(\mathrm{Nm} / \mathrm{rad}))\end{array}$ & $\begin{array}{c}\text { Torsional } \\
K_{z z} \\
(\mathrm{Nm} / \mathrm{rad}))\end{array}$ \\
\hline $\begin{array}{l}\text { Static stiffness or } \\
\text { equivalent stiffness }\end{array}$ & 30 & 300 & 250 & 2.5 & 1.0 & 0.8 \\
\hline
\end{tabular}


Table 3. First 10 natural frequencies of the bench-top micro milling machine

\begin{tabular}{cllll}
\hline \multirow{2}{*}{$\begin{array}{l}\text { Mode } \\
\text { No. }\end{array}$} & $\begin{array}{l}\text { Frequency } \\
(\mathrm{Hz})\end{array}$ & Description of mode & $\begin{array}{l}\text { Frequency } \\
(\mathrm{Hz})\end{array}$ & Description of mode \\
\hline 1 & 117.50 & Y and X slides rolling & 129.43 & Z slide pitch \\
\hline 2 & 142.09 & Z slide rolling & 142.05 & Z slide rolling \\
\hline 3 & 158.61 & X slide rolling + y axis bounce & 231.26 & Z slide bending \\
\hline 4 & 164.68 & X slide rolling & 292.10 & Z slide torsion \\
\hline 5 & 212.07 & Z slide bouncing & 343.57 & Y slide rolling \\
\hline 6 & 268.38 & Y slide rolling & 362.26 & X slide and frame bending \\
\hline 7 & 298.51 & Y slide pitch & 378.19 & Y slide pitch \\
\hline 8 & 319.03 & Complex vibration shapes & 404.81 & Complex vibration shapes \\
\hline 9 & 337.79 & Complex vibration shapes & 422.65 & Complex vibration shapes \\
\hline 10 & 406.74 & Complex vibration shapes & 515.08 & Complex vibration shapes \\
\hline
\end{tabular}


Table 4. Specifications of the micro milling machine - UltraMill

\begin{tabular}{|c|c|c|c|c|}
\hline Axes & $\mathrm{X}, \mathrm{Y}$ and $\mathrm{Z}$ axis & $\begin{array}{l}\text { B axis (rotary } \\
\text { table) }\end{array}$ & $\mathrm{C}$ axis & Spindle \\
\hline Type & \multicolumn{2}{|c|}{$\begin{array}{l}\text { Air bearing slides fitted with } \\
\text { squeeze film dampers }\end{array}$} & $\begin{array}{l}\text { Precision ball } \\
\text { bearing }\end{array}$ & Air bearing \\
\hline Stroke & $\begin{array}{l}X: 230 \mathrm{~mm} \\
Y: 225 \mathrm{~mm} \\
\mathrm{Z}: 160 \mathrm{~mm}\end{array}$ & $360^{\circ}$ & $\pm 90^{\circ}$ & N/A \\
\hline $\begin{array}{l}\text { Motion } \\
\text { accuracy }\end{array}$ & $\begin{array}{l}<1.0 \mu \mathrm{m} \text { over } \\
\text { total travel }\end{array}$ & $<1 \operatorname{arcsec}$ & $<10 \operatorname{arcsec}$ & $\begin{array}{l}<1.0 \mu \mathrm{m} \text { axial } \\
\text { TIR and }<2.0 \\
\mu \mathrm{m} \text { radial TIR }\end{array}$ \\
\hline Resolution & $5 \mathrm{~nm}$ & $0.02 \operatorname{arcsec}$ & $0.02 \operatorname{arcsec}$ & N/A \\
\hline Drive system & $\begin{array}{l}\text { brushless } \\
\text { Linear motor }\end{array}$ & $\begin{array}{l}\text { DC brushless } \\
\text { torque motor }\end{array}$ & $\begin{array}{l}\text { DC brushless } \\
\text { torque motor }\end{array}$ & $\begin{array}{l}\text { DC brushless } \\
\text { motor }\end{array}$ \\
\hline $\begin{array}{l}\text { Maximum } \\
\text { speed }\end{array}$ & $3000 \mathrm{~mm} / \mathrm{min}$ & $100 \mathrm{rpm}$ & $30 \mathrm{rpm}$ & 200,000 rpm \\
\hline
\end{tabular}

